frequent side effect with amitriptyline. More patients on lithium had multiple side effects.

What can we learn from this study? For patients with recurrent non-bipolar depression (at least three episodes in five years) lithium and amitriptyline provide some prophylaxis-but despite carefully controlled and monitored treatment most patients will still relapse. Probably in everyday clinical practice relapse rates would be much higher. Despite this positive finding further studies are needed. Both drugs have clinically important side effects while providing very imperfect protection against relapse. The choice between lithium or an antidepressant should, therefore, depend on other factors such as tolerance by the patient and long term toxicity. Though lithium has some advantages-it does not produce brief hypomanic attacks and blood concentrations can be easily monitored-many will conclude that its tendency to produce hypothyroidism, polyuria, and perhaps renal damage would make it a drug of second choice. Whichever prophylactic drug is used the evidence from this study is that it should be continued for at least three years.

The much more common clinical presentation is of a patient who has had only one or two depressive episodes. Should he or she continue to receive antidepressants and if so for how long? Mindham's study and subsequent work have shown clear benefit from antidepressant medication for at least six months. ${ }^{14}$ The case for continuing drugs for longer is still not clear. We do not know whether patients who get better with newer, non-tricyclic antidepressants should continue with them or be transferred to a well tried, proven, and much cheaper tricyclic drug for prophylaxis. Coppen et al suggested that maprotiline and mianserin are not as effective as lithium in preventing relapse. ${ }^{1516}$

The Medical Research Council has a distinguished record of promoting well designed and important trials in the management of affective disorders. Further trials are clearly needed to expand and continue the group 2 study reported here. We need a large study of unipolar depression, in both general practice and general psychiatric practice, looking at the clinical course, response to prophylactic treatment, and the level of morbidity both from the illness and from the treatment over a three to five year period.

Lithium, a tricyclic, and perhaps one or two of the newer non-tricyclic antidepressants should be compared. In all the studies so far patients have been withdrawn when they relapsed-but the real clinical world is not like that. The clinician still needs to know whether it is worth persevering with prophylaxis. Does one relapse mean that the drug should be stopped, or do patients who relapse still do better with some drug than with none at all?

So, though treatment of acute episodes of depression and prophylaxis against bipolar illness are often relatively successful, we are still not at all good at preventing recurrent depressive episodes by drugs-or at least by drugs alone. Whether other approaches such as cognitive psychotherapy either alone or in combination with drugs will prove to be more successful has yet to be established.

Senior Lecturer in Psychiatry,

C P FREEMAN

University of Edinburgh,

Royal Edinburgh Hospital,

Edinburgh EH10 5HF

I Glen AIM, Johnson AL, Shepherd M. Continuation therapy with lithium and amitriptyline in unipolar depressive illness: a randomized double-blind, controlled trial. Psychol Med 1984;14:37-50.

2 Boyd JH, Weissman MM. Epidemiology. In: Paykel ES, ed. Handbook of affective disorders. New

1978;35:705-12.
${ }^{4}$ Hagnel J, Lanke J, Rosrman B, Ojesjo L. Are we entering an age of melancholy? Depressive illness in a prospective epidemiological study over 25 years; the Lundby study, Sweden. Psychol Med
1982;12:279-89.

Angst J, Baastrup P, Graf P, Hippius H, Poldinger W, Weis P. The course of monopolar depression and bipolar psychosis. Psychiatrica Neurologia Neurochirurgia 1973;76:489-500.

${ }^{6}$ Lundquist G. Prognosis and course in manic depressive psychosis. A follow-up study of 319 first admissions. Acta Psychiatrica et Neurologica Scandinavica 1945;135(suppl): 1-96.

suang MT, Woolson RF. Excess mortality in schizophrenia and affective disorders. Arch Gen Psychiatry 1978;35:1181-s.

Prien RJ. Lithium in the prophylactic treatment of affective disorders. Arch Gen Psychiatry 1979;36:847-8.

列

eselow ED, Dunner DL, Fieve R, Loutin A. Lithium prophylaxis of depression in unipolar, bipolar Il and cyclothymic patie R, Loùn A. Lithe

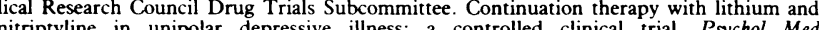
1981;11:409-16.

Spitzer RL, Endicott J, Robins E. Research diagnostic criteria $(R D C)$ for a selected group of functional disorders. New York: Biometrics Research, Psychiatric Institute, 1978.

Anonymous. Multicentre depression [Editorial]. Lancet 1981;ii:563-5.

Mindham RHS, Howland C, Shepherd M. An evaluation of continuation therapy with tricyclic antidepressants in depressive illness. Psychol Med 1973;3:5-17.

Coppen A, Montgomery SA, Gupta RK, Bailey JE. A double-blind comparison of lithium carbonate and maprotiline in the prophylaxis of the affective disorders. Br f Psychiatry 1976;128:479-85. Coppen A, Ghose K, Rao R, Bailey J, Peet M. Mianserin and lithium in the prophylaxis of
depression. Brf Psychiatry 1978;133:206-10.

\section{Double first in Wales}

Later this year Europe will get its first professor of health education and promotion and Britain its first large scale programme to prevent heart disease: the professor will be in Cardiff and will direct the heart programme, which will cover the whole of Wales. The new professor is to be Dr John Catford, who is at present a community physician in Winchester and leader of the Wessex Positive Health Team. He was also one of the main authors of the Canterbury report on preventing coronary heart disease. ${ }^{1}$

Britain needs such a heart programme because-as Professor Truswell explains in another leading article this week (p 509) - we are failing to reduce our death rates from heart disease as fast as many other Western countries. Much of this is due to governmental and public indifference, but a programme like those in North Karelia and Stanford would focus efforts on heart disease and show whether Britain is capable of developing, implementing, and evaluating such a programme. Wales is a good place to start because it has higher mortality from heart disease than England (about 10000 Welsh people die every year) and its own culture, administrations, and media.

But in the now traditional British manner both the programme and the chair have been underfunded by the Health Education Council, which has set aside $£ 11 / 2 \mathrm{~m}$ for five years. This works out at about $11 \mathrm{p}$ a year for each Welshman. The Canterbury report estimated that the cheapest effective programme would cost $30 \mathrm{p}$ a year for each person ${ }^{1}$; in other countries they have cost much more: North Karelia - 50p a year for each person, and Stanford at least a $£ 1$ a year. With these programmes (as with most things) you get what you pay for, and Dr Catford will have to spend much of his time at first scratching around for more money. A new director and professor could be much better employed.

The reason why we need a professor is that health promotion and education in Britain are in a mess. We have said before ${ }^{2}$ (and been much criticised for it $^{34}$ ) that the Health Education Council in London has taken a long time to make any impact. Since then the Scottish Health Education Group is widely deemed to have lost its way and the Health Education Council is still suffering purges. Academic respectability and an independent and powerful voice are badly needed by health promotion. What is wanted even more, of course, is a real commitment from the DHSS and the NHS to health promotion: perhaps 
rather than two underfunded and often ailing quangos we need a powerful office in central government with ramifications throughout the NHS and other bodies.

In the mean time, what can we expect from Dr Catford in Wales? The answer is not much in five years. It took 10 years to produce a fall in mortality from heart disease in North Karelia, and it will probably take as long in Wales. Professor Catford should not be thrown out if he has not produced the goods in five years. Let us hope, indeed, that in five years' time government, professional, and public commitment backed up by ample funds will see us well into what's been called the "second public health revolution."

1 Anonymous. Policies on prevention. Br Med f 1984;288:1182.

2 Anonymous. New thoughts for the Health Education Council. Br Med f 1984;285:1761-2.

3 Bailey BH, Player DA. New thoughts for the Health Education Council. Br Med f 1983;286:226.

4 McCron R. New thoughts for the Health Education Council. Br Med F 1983;286:645-6.

\section{Regular Review}

\section{Management of chronic urinary retention}

\section{J P MITCHELL}

In chronic urinary retention the residual urine remaining in the bladder after micturition has reached a volume equal to or greater than the normal bladder capacity. In acute retention the amount of urine withdrawn on catheterisation of the patient will be around 500 to $600 \mathrm{ml}$, but in chronic retention it will be $800 \mathrm{ml}$ or more. Patients with chronic retention most commonly present with a bladder content of something between 1000 and $1500 \mathrm{ml}$ but volumes above four litres have been described. ${ }^{1}$ The patient can still pass urine, but this large residue is left in the bladder after micturition.

Chronic urinary retention may be so insidious in onset that it is completely symptomless in the early stages. The patient may have no sense of incomplete emptying, and his volume of micturition does not produce any frequency. His bladder becomes insensitive so that he has no indication that it is already distended beyond its normal capacity. The patient may develop symptoms only when the first episodes of retention with overflow produce enuresis. In fact any form of incontinence in a man should alert the clinician to the possibility of chronic retention with overflow. Alternatively, patients with chronic retention may present with renal failure due to back pressure on the urinary tract. The patient may be losing weight and his appetite may diminish at the same time as he may become conscious of a slight increase in girth. The third possible presentation for chronic retention is when acute retention supervenes-the patient in chronic retention who has been passing urine suddenly finds that he is unable to do so. This state of acute on chronic retention differs from true acute retention in three respects. Firstly, the amount of pain is disproportionate to the size of the bladder - the patient does not appear to be in the intense discomfort that his distended bladder would be expected to produce. Secondly, the volume of urine in the bladder is greater than would be expected in straightforward acute retention. Thirdly, the inability to pass urine may last considerably longer than in simple acute retention. Patients with acute on chronic retention may even give a history of inability to pass urine for two days.

The distinction between straightforward acute retention and acute on chronic retention is important from the point of view not only of diagnosis but also of the prognosis and subsequent management. Chronic retention takes two forms, which are quite distinct in their clinical presentation. The distinguishing feature is the intravesical pressure. ${ }^{2}$ In high pressure chronic retention the pressure in the bladder is usually above $30 \mathrm{~cm} \mathrm{H} \mathrm{H}_{2} \mathrm{O}$ and the usual cause is obstruction to the urinary outflow or incoordination of the detrusor and sphincter mechanism. In low pressure retention the intravesical tension is less than $20 \mathrm{~cm} \mathrm{H}_{2} \mathrm{O}$ and the cause is usually failure of the detrusor muscle. High pressure retention may exert back pressure on the upper urinary tract, but the low pressure bladder, in total contrast, by its complete failure of the detrusor will protect the upper urinary tract from any back pressure.

Why some patients develop low and others high pressure retention remains one of the mysteries of urology, and why one patient with obstruction should develop acute retention and another chronic retention is also ill understood. As for the low tension bladder, the only similar condition in any other system in the body is Hirschsprung's disease of the colon, but no depopulation of neuromuscular synapses has been found to explain the failure of the detrusor muscle. The neurogenic bladder seen in spina bifida, in patients presenting with transverse myelitis, or in acute transection of the cord in spinal injury invariably produces the features of chronic retention, usually of the high pressure type. Incontinence from failure of the sphincter mechanism is an uncommon neurological disorder, the usual form of incontinence seen in patients with neurogenic bladders being the occasional overflow incontinence, most frequently noticed in those with spina bifida. Although the results of urodynamic investigations can distinguish between mechanical obstruction of the lower urinary tract and the incoordination of a dyssynergia of the sphincter mechanism, these studies have failed to throw any light on the reason why some patients should develop a high pressure chronic retention.

The complications of chronic retention are principally those of urinary stagnation. The risk of infection is increased and it may become rampant shortly after it is established, with the consequent probability of spread to the upper urinary tract. The second risk is of back pressure on ureters and kidneys. Necessarily the chance of damage to the upper urinary tract is considerably greater in high pressure chronic retention. 